\title{
Origin of Halogens and Nitrogen in Enstatite Chondrites
}

\author{
Alan E. Rubin · Byeon-Gak Choi
}

Received: 26 February 2009/Accepted: 7 May 2009/Published online: 26 May 2009

(C) The Author(s) 2009. This article is published with open access at Springerlink.com

\begin{abstract}
The EH and EL enstatite chondrites are the most reduced chondrite groups, having formed in nebular regions where the gas may have had high $\mathrm{C} / \mathrm{O}$ and/or $\mathrm{pH}_{2} / \mathrm{pH}_{2} \mathrm{O}$ ratios. Enstatite chondrites (particularly $\mathrm{EH}$ ) have higher $\mathrm{CI}-$ and $\mathrm{Mg}$-normalized abundances of halogens (especially $\mathrm{F}$ and $\mathrm{Cl}$ ) and nitrogen than ordinary chondrites and most groups of carbonaceous chondrites. Even relative to CI chondrites, EH and EL chondrites are enriched in F. We have found that literature values for the halogen abundance ratios in EH and EL chondrites are strongly correlated with the electronegativities of the individual halogens. We suggest that the most reactive halogens were the most efficient at forming compounds (e.g., halides) that were incorporated into EH-chondrite precursor materials. It seems plausible that, under the more-oxidizing conditions pertaining to the other chondrite groups, a larger fraction of the halogens remained in the gas. Nitrogen may have been incorporated into the enstatite chondrites as simple nitrides that did not condense under the more-oxidizing conditions in the regions where other chondrite groups formed. Literature data show that unequilibrated enstatite chondrites have light bulk $\mathrm{N}\left(\delta{ }^{15} \mathrm{~N} \approx-20 \%\right.$ o) compared to most ordinary $(-5$ to $+20 \%$ ) and carbonaceous $(+20$ to $+190 \%$ ) chondrites; this may reflect the contribution in enstatite chondrites of nitride condensates with $\delta^{15} \mathrm{~N}$ values close to the proposed nebular mean $(\sim-400 \%)$. In contrast, $\mathrm{N}$ in carbonaceous chondrites is mainly contained within ${ }^{15} \mathrm{~N}$-rich organic matter. The major carrier of $\mathrm{N}$ in ordinary chondrites is unknown.
\end{abstract}

Keywords Chondrites - Enstatite chondrites $\cdot$ Halogens $\cdot$ Nitrogen $\cdot$ Electronegativity

\author{
A. E. Rubin $(\bowtie) \cdot$ B.-G. Choi \\ Institute of Geophysics and Planetary Physics, University of California, Los Angeles, CA 90095-1567, \\ USA \\ e-mail: aerubin@ucla.edu \\ B.-G. Choi \\ Department of Earth Science Education, Seoul National University, Seoul 151-748, Republic of Korea
}




\section{Introduction}

Enstatite chondrites comprise two groups-EH (high total iron) and EL (low total iron)that are the most reduced chondritic samples in our collections. These meteorites are important because they may have formed in the inner solar system (Wasson 1988) and contributed substantially to the accretion of the terrestrial planets. The scarcity of $\mathrm{FeO}$ in Mercury's spectrum (Vilas 1985) and Mercury's high inferred metal/silicate ratio led Wasson (1988) to suggest that Mercury was formed from materials related to enstatite chondrites. The rare gas abundances of the Venusian atmosphere (Donahue and Pollack 1983) resemble those of EH chondrites (Crabb and Anders 1981), suggesting that many of the building blocks of Venus were enstatite chondrites (Wasson 1988). The O- and $\mathrm{N}$-isotopic bulk compositions of enstatite chondrites are similar to those of Earth and Mars (e.g., Clayton 1993; Javoy 1995; Mohapatra and Murty 2003), leading some workers to suggest that these planets also accreted largely from enstatite-chondrite-like materials (e.g., Jagoutz et al. 1979; Javoy 1995).

The great state of reduction of the enstatite chondrites is reflected in their mineralogy and modal mineral abundances. These rocks are characterized by (1) graphite and Si-rich metallic Fe (e.g., Keil 1968; Ramdohr 1973), (2) very low concentrations of oxidized iron (e.g., 0.02-0.04 mol\% Fs in EL6 enstatite grains; Wasson et al. 1994), (3) high modal abundances of kamacite (e.g., 20-25 wt\%; Keil 1968), and (4) abundant sulfide ( $\sim 10 \mathrm{wt} \%$; Keil 1968). Primary sulfide phases include oldhamite (CaS), niningerite $(\mathrm{Mg}, \mathrm{Fe}) \mathrm{S}$, ferroan alabandite $(\mathrm{Mn}, \mathrm{Fe}) \mathrm{S}$, daubréelite $\left(\mathrm{FeCr}_{2} \mathrm{~S}_{4}\right)$, caswellsilverite $\left(\mathrm{NaCrS}_{2}\right)$, and Ti-bearing troilite $(\mathrm{FeS})$; all of these minerals contain elements that are mainly lithophile under more oxidizing conditions.

The fugacities of some of the gas phases in the local region of the nebula where the enstatite chondrites formed may have been non-solar: e.g., the $\mathrm{C} / \mathrm{O}$ ratio of the gas may have been close to unity (in contrast to the solar ratio of 0.6) (e.g., Lattimer et al. 1978; Larimer and Bartholomay 1979) and/or the $\mathrm{pH}_{2} / \mathrm{pH}_{2} \mathrm{O}$ ratio may have been above solar values (e.g., Wasson and Kallemeyn 1988). The high sulfide contents of enstatite chondrites (e.g., $\sim 12 \mathrm{wt} \%$ in $\mathrm{EH}$ vs. $\sim 5 \mathrm{wt} \%$ in $\mathrm{H}$ chondrites; Keil 1968, 1962) also suggest a high $\mathrm{pH}_{2} \mathrm{~S} / \mathrm{pH}_{2}$ ratio in the gas (Wasson and Kallemeyn 1988), an inference consistent with experimental studies (e.g., Lauretta et al. 1997).

Enstatite chondrites (particularly EH chondrites) contain higher CI-normalized abundances of some volatile and moderately volatile elements than other chondrite groups (e.g., Anders 1964; Baedecker and Wasson 1975; Palme et al. 1988; Davis 2006). For these reduced, metal- and sulfide-rich meteorites, moderately volatile elements that are enriched include siderophiles (e.g., Ga, As, Sb, and Au), chalcophiles (e.g., S, Se), and P. (Under reducing conditions, $\mathrm{P}$ alloys with metal and forms phosphide and silicide phases associated with metal (e.g., Keil 1968; Reed 1968).) The other volatile and moderately volatile elements that are highly enriched in enstatite chondrites are the halogens and nitrogen. This paper explores the possibility that the enrichment in halogens and nitrogen may have been facilitated by the reducing conditions under which the enstatite chondrites formed.

\section{Sources of Data}

The bulk compositional data in Table 1 are unitless CI- and Mg-normalized abundance ratios. Most of the data are from the compilation of Wasson and Kallemeyn (1988); the N data in EH and EL chondrites are from Grady et al. (1986). Patzer et al. (2004) determined 
Table 1 Fifty-percent equilibrium condensation temperatures and CI- and Mg-normalized abundances of halogens and nitrogen in major chondrite groups

\begin{tabular}{|c|c|c|c|c|c|c|c|c|c|c|c|}
\hline & \multirow[t]{2}{*}{$50 \% \mathrm{~T}_{\mathrm{c}}(\mathrm{K})$} & \multicolumn{2}{|c|}{ Electronegativity } & \multirow[t]{2}{*}{ EH } & \multirow[t]{2}{*}{ EL } & \multirow[t]{2}{*}{$\mathrm{H}$} & \multirow[t]{2}{*}{$\mathrm{L}$} & \multirow[t]{2}{*}{ LL } & \multirow[t]{2}{*}{$\mathrm{CM}$} & \multirow[t]{2}{*}{$\mathrm{CO}$} & \multirow[t]{2}{*}{$\mathrm{CV}$} \\
\hline & & A-R & Pauling & & & & & & & & \\
\hline \multicolumn{12}{|c|}{ Halogens (volatile to moderately volatile) } \\
\hline $\mathrm{F}$ & 734 & 4.10 & 3.98 & 3.40 & 1.93 & 0.35 & 0.42 & 0.62 & 0.49 & 0.31 & 0.25 \\
\hline $\mathrm{Cl}$ & 948 & 2.83 & 3.16 & 0.89 & 0.21 & 0.08 & 0.07 & 0.12 & 0.20 & 0.24 & 0.21 \\
\hline $\mathrm{Br}$ & 546 & 2.74 & 2.96 & 0.61 & 0.15 & 0.10 & 0.14 & 0.11 & 0.60 & 0.24 & 0.28 \\
\hline I & 535 & 2.21 & 2.66 & 0.27 & 0.07 & 0.09 & 0.07 & - & 0.70 & 0.27 & 0.25 \\
\hline \multicolumn{12}{|c|}{ Nitrogen (highly volatile) } \\
\hline $\mathrm{N}$ & 123 & 3.07 & 3.04 & 0.33 & 0.22 & 0.02 & 0.02 & 0.03 & 0.84 & 0.04 & 0.04 \\
\hline
\end{tabular}

Condensation temperatures are for a solar-system-composition gas at a total pressure of $10^{-4}$ bar (Lodders, 2003). Most chondrite abundances are calculated from Wasson and Kallemeyn (1988); the EL-chondrite data are based only on EL6 chondrites. Nitrogen values in EH and EL chondrites are based on Grady et al. (1986). A-R = Allred-Rochow electronegativity value; Pauling = Pauling scale electronegativity value

the bulk composition of the Grein 002 EL4 impact-melt breccia and reported concentrations of $\mathrm{Br}, \mathrm{N}$, and $\mathrm{Mg}$ (among other elements). Their CI- and Mg-normalized $\mathrm{Br}$ and $\mathrm{N}$ abundances are 0.27 and 0.22, respectively, compared to 0.15 and 0.22 in EL6 chondrites (Table 1). In the discussion below, we use the values listed in Table 1.

The halogen values listed in Wasson and Kallemeyn (1988) are based on original data determined by a variety of methods including neutron activation analysis and spectrophotometric techniques. Wasson and Kallemeyn (1988) evaluated the original data, constructed multi-element plots looking for smooth chondritic trends, and determined weighted means for each element. Uncertainties in the original data reflect actual sampleto-sample compositional variations, analytical uncertainties (including counting statistics and incomplete yields), and laboratory contamination. The uncertainties are $\sim 25 \%$ for $\mathrm{F}$ (Reed 1964; Greenland and Lovering 1965; Allen and Clark 1977), 50\% for Cl (Greenland and Lovering 1965; von Gunten et al. 1965; Reed and Allen 1966; Goles et al. 1967; Quijano-Rico and Wänke 1969), 20\% for Br (Kallemeyn and Wasson 1986), and

$\sim 40 \%$ for I (Goles and Anders 1962; Reed and Allen 1966; Goles et al. 1967).

The $\mathrm{N}$ abundances in EH and EL chondrites are based on the stepped pyrolysis experiments of Grady et al. (1986) and have errors of $<5 \%$. Nitrogen abundances for other chondrite groups in Table 1 are derived from Wasson and Kallemeyn (1988).

All of the EL data in Table 1 are based on EL6 chondrites. EL chondrites of petrologic type $<6$ were recognized only after the Wasson and Kallemeyn (1988) compilation was published: EL3 (MAC 88136; Lin et al. 1991; Lin and El Goresy 2002); EL4 (QUE 94368 and Grein 002; Rubin 1997a; Patzer et al. 2004); EL5 (Tanezrouft 031 and TIL 91714; Rubin et al. 1997).

\section{Discussion}

\subsection{Bulk Abundances of Halogens and Nitrogen in EH and EL Chondrites}

Reed (1964) pointed out that the F abundance in different chondrite groups is roughly correlated with a particular group's degree of oxidation: $\mathrm{F}$ is highest in enstatite chondrites 
and appreciably lower in both ordinary chondrites and carbonaceous chondrites (Table 1). Chlorine, Br, and I have higher concentrations in CI chondrites than in other chondrite groups (Wasson and Kallemeyn, 1988). Nevertheless, $\mathrm{Cl}$ shows a pattern similar to that of $\mathrm{F}$ : it is higher in enstatite chondrites than in ordinary chondrites or $\mathrm{CM}, \mathrm{CO}$ and $\mathrm{CV}$ chondrites. The $\mathrm{Br}$ abundance ratio in $\mathrm{EH}$ chondrites is essentially equivalent to that in $\mathrm{CM}$ chondrites and higher than those in other non-CI chondrite groups. The EL-chondrite $\mathrm{Br}$ abundance (Table 1) is slightly higher than those in ordinary chondrites, but lower than those in carbonaceous chondrites. (Although we are not considering the high $\mathrm{Br}$ abundance of 0.27 determined by Patzer et al. (2004) for Grein 002, inclusion of this datum would not change the general trends.) Iodine is highest in CM, appreciably lower in $\mathrm{EH}$ and $\mathrm{CO}$, slightly lower still in $\mathrm{CV}$, and much lower in ordinary chondrites and EL chondrites. The $\mathrm{N}$ abundances in EH and EL chondrites are appreciably lower than those in CI and CM chondrites, but much higher than those in other chondrite groups.

EH chondrites are richer in halogens and nitrogen than EL chondrites (Table 1). Although these differences in elemental abundances may, in part, have been inherited from the solar nebula, the EL-chondrite data compiled by Wasson and Kallemeyn (1988) are based solely on EL6 chondrites. These rocks were thermally metamorphosed and many have been interpreted as having been shock heated (e.g., Rubin 1983a, b, 1984, 1997a, b, 2006; Rubin et al. 1997); such processes plausibly resulted in the loss of an appreciable fraction of volatiles (Rubin et al. 2009) and could also have caused fractionation of $\mathrm{N}$ isotopes (Mohapatra and Murty 2004). Unfortunately, no halogen or nitrogen data other than those of Patzer et al. (2004) for Br and N in Grein 002 are presently available for EL3, EL4, or EL5 chondrites.

\subsection{Occurrences of Halogens}

Among the halogens, $\mathrm{F}$ and $\mathrm{Cl}$ occur in measurable quantities in only a few phases in enstatite chondrites; the principal carriers of $\mathrm{Br}$ and I have not yet been identified.

(1) Fluor-richterite, an amphibole of formula $\mathrm{Na}_{2} \mathrm{Ca}(\mathrm{Mg}, \mathrm{Fe})_{5} \mathrm{Si}_{8} \mathrm{O}_{22} \mathrm{~F}_{2}$ that contains $\sim 4.0-4.5 \mathrm{wt} \% \mathrm{~F}$, occurs in the matrix of Abee (where it is present as rare 3.5-mmlong acicular grains; Douglas and Plant 1969; Olsen et al. 1973) and in St. Sauveur (where it occurs as $\sim 40 \times 100-\mu \mathrm{m}$-size subhedral grains; Rubin 1983c). Both of these EH chondrites have been interpreted as impact-melt breccias (Rubin and Scott 1997; Rubin et al. 1997; Keil 2007). A few aubrites also contain fluor-richterite (Bevan et al. 1977; Lin and Kimura 1998). The fluor-richterite grains in the Mayo Belwa aubrite contain $7.2 \mathrm{wt} \% \mathrm{Na}_{2} \mathrm{O}, 3.9 \mathrm{wt} \% \mathrm{~F}$, and $0.48 \mathrm{wt} \% \mathrm{~K}_{2} \mathrm{O}$ (Table II of Bevan et al. 1977), demonstrating that this volatile-bearing phase can form by crystallization from a melt. Rubin (2009) recently described Mayo Belwa as an aubrite impact-melt breccia.

(2) Fluorphlogopite, a phyllosilicate of formula $\mathrm{KMg}_{3}\left(\mathrm{Si}_{3} \mathrm{Al}\right) \mathrm{O}_{10} \mathrm{~F}_{2}$ that averages $5.1 \mathrm{wt} \% \mathrm{~F}$, is present in the $\mathrm{EH}$ impact-melt rock Y 82189; it occurs as rare subhedral, $10-30-\mu \mathrm{m}$-size grains in association with enstatite, silica, and albite (Lin and Kimura 1998).

(3) Djerfisherite $\left(\mathrm{K}_{\mathbf{6}} \mathrm{Na} \mathbf{9}(\mathrm{Fe}, \mathrm{Cu})_{\mathbf{2 4}} \mathrm{S}_{\mathbf{2 6}} \mathrm{Cl}\right.$ ) (which contains $\sim 1.5 \mathrm{wt} \% \mathrm{Cl}$; El Goresy et al. 1988; Lin and El Goresy 2002) forms millimeter-size clasts and veins in the matrix of EH3 Qingzhen, but is virtually absent from Qingzhen chondrules (Grossman et al. 1985; El Goresy et al. 1988). It also occurs in other EH3 chondrites and as an accessory phase in EL3 chondrites (e.g., MAC 88136; Lin et al. 1991). 
(4) Chondrule glass in Qingzhen contains up to $4.4 \mathrm{wt} \% \mathrm{Cl}$ (I and $\mathrm{F}$ were not determined; Grossman et al. 1985; El Goresy et al. 1988). Chlorine-rich glass also occurs in EL3 MAC 88136 (Lin et al. 1991).

(5) Lawrencite $\left(\mathrm{FeCl}_{2}\right)$ was reported in the EH4 Indarch fall occurring as thin rims around silica grains, as inclusions within kamacite and troilite, and as isolated grains in the matrix associated with enstatite (Keil 1968). (Buchwald and Clarke (1989) called lawrencite a "mineralogical chimera" and found that the Cl-bearing phase associated with the metal in iron meteorites and ordinary chondrites is akaganéite, $\beta$-FeOOH, in many cases associated with goethite, $\alpha-\mathrm{FeO}(\mathrm{OH})$. Nevertheless, the Fe- and Cl-bearing rims around silica grains in Indarch (Fig. 3 of Keil 1968) are unlikely to be alteration products of metallic Fe-Ni.)

\subsection{Condensation of Halogens}

As shown in Fig. 1, the halogen abundance ratios in enstatite chondrites (Table 1) are not correlated with volatility (i.e., with the $50 \%$ equilibrium condensation temperatures of the elements from a gas with canonical solar-nebula compositions; Table 1), i.e., EH: $r=0.295, n=4,2 \alpha=0.76$ (significant only at the $24 \%$ confidence level for a two-tailed test); EL: $r=0.190, n=4,2 \alpha=0.85$ (significant at the $15 \%$ confidence level). (For these statistical tests, $r$ is the correlation coefficient, $n$ is the number of samples, and $2 \alpha$ is the significance level for a two-tailed test. The significance level is the probability of erroneously rejecting the null hypothesis when that hypothesis is true, i.e., committing a Type I error.)

These results indicate that the halogen abundances in enstatite chondrites did not result mainly either from (1) chondrite agglomeration prior to the complete condensation of the halogens from gas with the canonical solar composition or (2) preferential loss of the morevolatile halogen species from enstatite-chondrite materials due to heating (e.g., chondrule formation or parent-body thermal or shock metamorphism). Nevertheless, it is possible that



Fig. 1 Plot of halogen abundances (normalized to $\mathrm{Mg}$ and to $\mathrm{CI}$ chondrites) in $\mathrm{EH}$ and EL chondrites versus the $50 \%$ equilibrium condensation temperatures of the elements from a solar-composition gas. No correlations are evident. Abundance data from Wasson and Kallemeyn (1988) 
the EL data (which is based solely on EL6 chondrites) may have been affected by parentbody processing.

In contrast, we find that the halogen abundance ratios in enstatite chondrites are correlated with the electronegativities (Allred-Rochow values) of the individual elements (Fig. 2): $\mathrm{F}$ (4.10), $\mathrm{Cl}$ (2.83), $\mathrm{Br}$ (2.74), and I (2.21). If we assume that the correlations are linear, we find that they are strong in both groups, i.e., EH: $r=0.982,2 \alpha=0.02$, (significant at the $98 \%$ confidence level for a two-tailed test); EL: $r=0.959,2 \alpha=0.05$ (significant at the $95 \%$ confidence level for a two-tailed test). The Pauling scale electronegativity values are similar $(F=3.98, \mathrm{Cl}=3.16, \mathrm{Br}=2.96$, and $I=2.66)$ and produce similarly strong correlations.

The linear correlations between electronegativity and halogen abundance for the ordinary chondrites are somewhat lower (Fig. 3) and are due in part to the high abundance of $\mathrm{F}$ relative to those of the other halogens (thus approximating two-point correlations): $\mathrm{H}$ $(r=0.935,2 \alpha=0.09), \mathrm{L}(r=0.947,2 \alpha=0.07)$. There are no significant correlations between halogen abundance ratio and electronegativity for the carbonaceous chondrites: $\mathrm{CM}(r=-0.278), \mathrm{CO}(r=0.706)$, and CV $(r=-0.019)$.

Under relatively oxidizing conditions, the halogens condense in apatite $\left[\mathrm{Ca}_{5}\left(\mathrm{PO}_{4}\right)_{3}\right.$ $(\mathrm{F}, \mathrm{Cl})]$ or sodalite $\left[\mathrm{Na}_{4}\left(\mathrm{Si}_{3} \mathrm{Al}_{3}\right) \mathrm{O}_{12} \mathrm{Cl}\right]$ (Lodders 2003), but under the reducing conditions pertaining to the enstatite chondrites, phosphate and sodalite are absent (Keil 1968; Rubin 1997c). The halogens are very reactive and the correlation between abundance and electronegativity in enstatite chondrites suggests that, under reducing conditions, the most reactive halogens were the most efficient at forming compounds that were incorporated into enstatite-chondrite precursor materials. These may have included simple metal halides such as $\mathrm{FeCl}_{2}, \mathrm{MgF}_{2}, \mathrm{FeBr}_{2}, \mathrm{MgI}_{2}$, etc. Lawrencite $\left(\mathrm{FeCl}_{2}\right)$ is the only simple halide that has so far been identified in enstatite chondrites (Keil 1968).

At least some of the minor phases that are rich in halogens may be secondary. If so, then this indicates that these elements were redistributed during parent-body processing. In turn, this may explain why few of the proposed simple metal halides have been identified in these chondrites.



Fig. 2 Plot of halogen abundances (normalized to $\mathrm{Mg}$ and to $\mathrm{CI}$ chondrites) in $\mathrm{EH}$ and EL chondrites versus elemental electronegativity (Allred-Rochow values). Abundance data from Wasson and Kallemeyn (1988) 


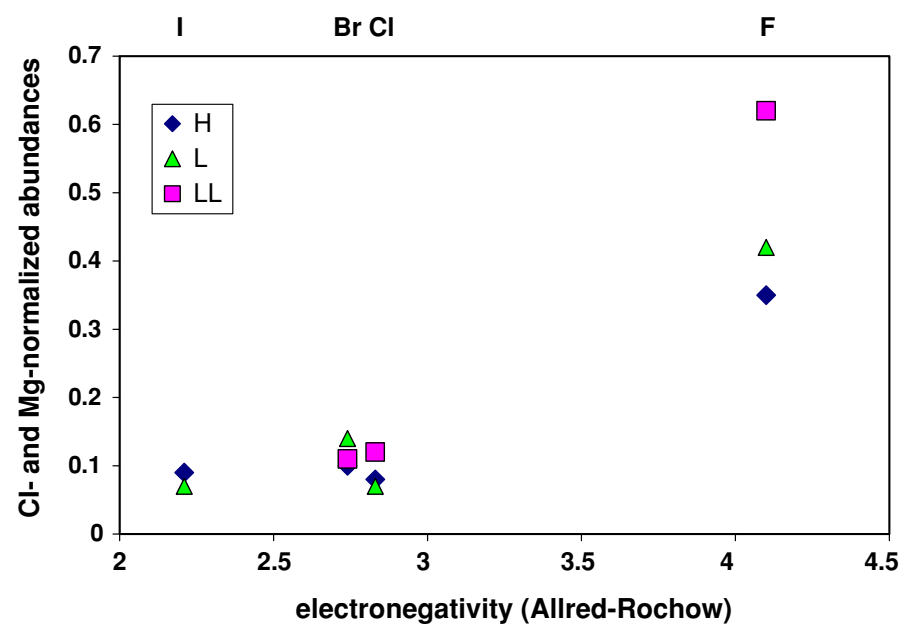

Fig. 3 Plot of halogen abundances (normalized to $\mathrm{Mg}$ and to CI chondrites) in $\mathrm{H}$, L, and LL ordinary chondrites versus elemental electronegativity (Allred-Rochow values). Abundance data from Wasson and Kallemeyn (1988)

The high abundance of $\mathrm{F}$ in the ordinary chondrites compared to those of the other halogens suggests that the $\mathrm{F}$ enrichment in ordinary chondrites may have been due to the same mechanism that caused its enrichment in enstatite chondrites, i.e., to the incorporation of a simple metal fluoride during accretion. Nevertheless, because the F contents of ordinary chondrites are much lower than those in enstatite chondrites, the process must have been much less efficient.

The lower halogen abundances in other chondrite groups (Table 1) implies that, under the more-oxidizing ambient nebular conditions that characterized the local environments where these other groups formed, a larger fraction of the halogens remained in the gas.

\subsection{Occurrences of Nitrogen}

The three principal $\mathrm{N}$-rich minerals in enstatite chondrites are osbornite (TiN), sinoite $\left(\mathrm{Si}_{2} \mathrm{~N}_{2} \mathrm{O}\right)$, and nierite $\left(\alpha-\mathrm{Si}_{3} \mathrm{~N}_{4}\right)$.

Graphite, an accessory constituent of enstatite chondrites (constituting, for example, 0.04 wt\% of EH4 Indarch and 0.46 wt\% of EH5 St. Mark's; Table 2 of Keil 1968), contains small amounts of N. Individual occurrences of graphite in EH5 St. Mark's contain 300-1,200 ppm N and average $632 \pm 321$ ppm N ( $n=13$; e.g., Mostefaoui et al. 2005). Graphite in St. Mark's therefore accounts for $2.9 \mathrm{ppm} \mathrm{N}$ in the whole rock. Stepped combustion and stepped pyrolysis experiments by Grady et al. (1986) indicate that the St. Mark's whole rock contains $195 \mathrm{ppm} \mathrm{N}$. It is thus apparent that only about $1.5 \%$ of the N in St. Mark's is in graphite.

The low solubility of $\mathrm{N}_{2}$ (g) in kamacite (e.g., Fegley 1983) implies that little of the $\mathrm{N}$ in enstatite chondrites is derived from the metal. Nevertheless, small amounts of $\mathrm{N}$ may be present in graphite grains intergrown with kamacite.

Osbornite occurs in impact-melted enstatite chondrites, a few EL6 chondrites (some of which may have been partly impact melted; e.g., Rubin 2006), and a few aubrites (e.g., Derham et al. 1964; Buseck and Holdsworth 1972; Ramdohr 1973). Kinsey et al. (1995) 
found $15-\mu \mathrm{m}$-size osbornite grains inside an impact-melt-rock clast in EL6 Hvittis. McCoy et al. (1995) reported a few 10- to 20- $\mu \mathrm{m}$-size osbornite grains in the Ilafegh $009 \mathrm{EL}$ impact-melt rock and a single $15 \times 30 \mu \mathrm{m}$ grain in impact-melted regions of the Happy Canyon EL impact-melt breccia. Patzer et al. (2004) identified a few 1- to 10- $\mu \mathrm{m}$-size grains of osbornite in EL4 Grein 002, a partly impact-melted rock.

The occurrence of numerous small grains of osbornite in the Stardust sample of Comet Wild 2 indicates that this phase also formed by condensation in the solar nebula (Brownlee et al. 2008), consistent with condensation calculations (e.g., Fegley 1983; Petaev et al. 1987; Lodders and Amari 2005).

Sinoite occurs as 10 - to $210-\mu \mathrm{m}$-size subhedral and euhedral grains in impact-melted portions of EL4 QUE 94368 (Rubin 1997a) and as heterogeneously distributed euhedral grains in EL4 Grein 002 (Patzer et al. 2004). Sinoite has also been reported in an EL5 chondrite (TIL 91714) and in at least 10 EL6 chondrites (e.g., Rubin et al. 1997; Bischoff and Zipfel 2003; Bischoff et al. 2005; Rubin 2006). Although Muenow et al. (1992) suggested that the EL6 sinoite grains formed by thermal metamorphism over long periods of time, in view of the interpretation that many of the EL6 chondrites are annealed impactmelt breccias (e.g., Rubin et al. 1997; Rubin 2006), it seems plausible that sinoite in these rocks formed by crystallization from impact melts (Rubin 1997a; Bischoff et al. 2005). Consistent with this model is the report of Lee et al. (1995) that identified a single sinoite grain in a perchloric-acid-resistant residue of Abee, a rock interpreted to be an EH impactmelt breccia (Rubin and Scott 1997; Rubin et al. 1997).

Nierite was reported in EH3 Qingzhen and EH4 Indarch as tiny $(0.1-10 \mu \mathrm{m})$ grains associated with kamacite, perryite and schreibersite, phases that contain metallic Si in solid solution (Alexander et al. 1994; Lee et al. 1995; Russell et al. 1995). Most of the nierite grains have solar $\mathrm{Si}-, \mathrm{N}$ - and $\mathrm{C}$-isotopic compositions, indicating that they are unlikely to be presolar (Alexander et al. 1994). The high nebular pressures $(\sim 1 \mathrm{~atm})$ required for nierite to condense at temperatures $>400^{\circ} \mathrm{C}$ from a gas with a solar $\mathrm{H} / \mathrm{N}$ ratio led Alexander et al. (1994) to suggest that the nierite grains in EH3 and EH4 chondrites formed during parent-body thermal metamorphism.

\subsection{Condensation of Nitrogen}

Nitrogen in the solar nebula occurs mainly as $\mathrm{N}_{2}$ and, to a lesser extent, as $\mathrm{NH}_{3}$; the overall $\mathrm{N}_{2} / \mathrm{NH}_{3}$ ratio of the nebula was $\sim 4$ (Womack et al. 1992). Molecular nitrogen and ammonia are highly volatile phases that remained in the gas down to very low temperatures; thus, little nitrogen was incorporated into ordinary chondrites, $\mathrm{CO}$, and $\mathrm{CV}$ chondrites. The comparatively high $\mathrm{N}$ contents of $\mathrm{CI}$ and $\mathrm{CM}$ chondrites are due mainly to the high modal abundances of soluble and insoluble N-bearing organic compounds in these rocks (e.g., Cronin et al. 1988; Pizzarello et al. 2006).

Nitrogen has a very high electronegativity (with an Allred-Rochow value of 3.07 and a Pauling-scale value of 3.04). In the enstatite-chondrite region of the nebula, where the $\mathrm{pH}_{2} \mathrm{~S} / \mathrm{pH}_{2}$ ratio may have been high and ambient conditions were reducing, small amounts of $\mathrm{N}$ could have reacted with various common species to produce condensable compounds (e.g., TiN, $\mathrm{Si}_{3} \mathrm{~N}_{4}$, and $\mathrm{S}_{4} \mathrm{~N}_{4}$ ) that were incorporated into agglomerating $\mathrm{EH}$ and $\mathrm{EL}$ chondrites. Some of these phases may have condensed and then been destroyed and/or redistributed during parent-body processing. (Although $\mathrm{AlN}$ is expected to condense from the nebula, it converts to $\mathrm{Al}_{2} \mathrm{O}_{3}$ and other Al-bearing phases as the nebula continues to cool (Lodders and Amari 2005)). 
The $\mathrm{N}$-isotopic compositions of enstatite chondrites are a mixture of different $\mathrm{N}$ components (Mohapatra et al. 2003). Enstatite chondrites have isotopically light N: bulk $\delta^{15} \mathrm{~N}$ values are typically -10 to $-45 \%$ (e.g., Grady et al. 1986); Mohapatra and Murty (2003) calculated a mean $\delta^{15} \mathrm{~N}$ value of $-28 \pm 10 \%$. Ordinary chondrites $(-5$ to $+20 \%$; Kung and Clayton 1978) and many carbonaceous chondrites (+20 to $+190 \%$; Kung and Clayton 1978; Kerridge 1980; Robert and Epstein 1980; Robert et al. 1980) have heavier $\mathrm{N}$. Some workers have suggested that the $\mathrm{N}$-isotopic differences among these chondrite groups are not primordial, but rather result from thermal metamorphism and/or aqueous alteration of enstatite chondrites and concomitant loss of ${ }^{15} \mathrm{~N}$-rich labile organic matter (e.g., Sephton et al. 2003; Pearson et al. 2006).

However, even relatively unequilibrated EH chondrites (e.g., EH3 Kota-Kota and EH4 Indarch) have isotopically light $\mathrm{N}\left(\delta^{15} \mathrm{~N} \approx-20 \%\right.$; Grady et al. 1986). These low values may reflect the contribution of nitride condensates from the nebula that had $\delta^{15} \mathrm{~N}$ values close to the proposed nebular mean $(\sim-360 \%$ to $-400 \%$, as estimated from Hashizume et al. 2000; Fouchet et al. 2000; Owen et al. 2001; and Meibom et al. 2007).

If we assume that chondrites have a mean $\delta^{15} \mathrm{~N}$ value of $\sim 40 \%$ o (close to the bulk $\mathrm{N}$-isotopic composition of CI and CM chondrites as given in the literature and determined by the pyrolysis and sealed-tube-digestion kjeldahl methods; Table 1 of Kung and Clayton 1978) and that enstatite chondrites have a bulk $\delta^{15} \mathrm{~N}$ value of $-20 \%$, then mass-balance calculations show that $\sim 15 \%$ of the $\mathrm{N}$ in enstatite chondrites is contained in isotopically light $\mathrm{N}$ condensates with an $\delta^{15} \mathrm{~N}$ value of $-400 \%$. (If $\mathrm{N}$ in ordinary chondrites comprise the same components and has a mean $\delta^{15} \mathrm{~N}$ value of $\sim 15 \%$ (Kung and Clayton 1978), then $\sim 5 \%$ of bulk ordinary-chondrite $\mathrm{N}$ would consist of condensates with a $\delta^{15} \mathrm{~N}$ value of $-400 \%$. However, there are little data on where $\mathrm{N}$ is sited in ordinary chondrites.) Carbonaceous chondrites probably lack such a component (or possess it in very low abundances); instead, the $\mathrm{N}$-isotopic compositions of $\mathrm{CI}$ and $\mathrm{CM}$ chondrites are dominated by ${ }^{15} \mathrm{~N}$-rich organic matter (e.g., Aléon and Robert 2004).

\section{Conclusions}

Halogen abundance ratios in EH and EL chondrites are strongly correlated with the electronegativities of the individual halogens. Reducing conditions prevailed at the time and place in the solar nebula where the mineral precursors of enstatite chondrites condensed. These conditions may have been caused by high $\mathrm{C} / \mathrm{O}$ ratios and/or high $\mathrm{pH}_{2} / \mathrm{pH}_{2} \mathrm{O}$ ratios in the local gas; the high modal abundances of sulfide phases in enstatite chondrites suggest that the $\mathrm{pH}_{2} \mathrm{~S} / \mathrm{pH}_{2}$ ratio may also have been elevated. Because of the reducing conditions, enstatite chondrites (particularly $\mathrm{EH}$ chondrites) became enriched relative to most other chondrite groups in halogens (mainly $\mathrm{F}$ and, to a lesser extent, $\mathrm{Cl}$ ) and nitrogen. These elements may have condensed as simple halides and nitrides, respectively, that were destroyed and/or redistributed during parent-body processing. Under the more-oxidizing conditions pertaining to the other chondrite groups, larger fractions of $\mathrm{N}$ and the halogens remained in the gas.

Acknowledgments We thank J. T. Wasson, K. Keil and K. Lodders for useful comments and T. Stephan for a helpful review. Reviews of an earlier version of this manuscript were provided by J. Wade, A. El Goresy, U. Krähenbühl, R. K. Mohapatra and an anonymous referee. This work was supported in part by NASA grant NNG06GF95G (A. E. Rubin) and Korea Science and Engineering Foundation (KOSEF) grant R01-2006-000-10522-0 (B.-G. Choi). 
Open Access This article is distributed under the terms of the Creative Commons Attribution Noncommercial License which permits any noncommercial use, distribution, and reproduction in any medium, provided the original author(s) and source are credited.

\section{References}

J. Aléon, F. Robert, Interstellar chemistry recorded by nitrogen isotopes in Solar System organic matter. Icarus 167, 424-430 (2004). doi:10.1016/j.icarus.2003.10.012

C.M.O'.D. Alexander, P. Swan, C.A. Prombo, Occurrence and implications of silicon nitride in enstatite chondrites. Meteoritics 29, 79-85 (1994)

R.O. Allen, P.J. Clark, Fluorine in meteorites. Geochim. Cosmochim. Acta 41, 581-585 (1977). doi:10.1016/ 0016-7037(77)90299-X

E. Anders, Origin, age and composition of meteorites. Space Sci. Rev. 3, 583-714 (1964). doi:10.1007/ BF00177954

P.A. Baedecker, J.T. Wasson, Elemental fractionations among enstatite chondrites. Geochim. Cosmochim. Acta 39, 735-765 (1975). doi:10.1016/0016-7037(75)90013-7

A.W.R. Bevan, J.C. Bevan, J.G. Francis, Amphibole in the Mayo Belwa meteorite: First occurrence in an enstatite achondrite. Mineral. Mag. 41, 531-534 (1977). doi:10.1180/minmag.1977.041.320.20

A. Bischoff, J. Zipfel, Mineralogy of the Neuschwanstein (EL6) chondrite-First results. Lunar Planet. Sci. 34, abstract\# 1212, Lunar and Planetary Institute, Houston (2003)

A. Bischoff, T. Grund, T. Jording, B. Heying, R.-D. Hoffmann, U.C. Rodewald, R. Pottgen, Occurrence, structure, and formation of sinoite in enstatite chondrites. Meteorit. Planet. Sci. 40, A20 (2005). abstract

D.E. Brownlee, D.J. Joswiak, G. Matrajt, J.P. Bradley, D.S. Ebel, Ultra-refractory attogram inclusions in comet dust-first condensates? Lunar Planet. Sci. 39, abstract\#1978 (2008)

V.F. Buchwald, R.S. Clarke, Corrosion of Fe-Ni alloys by Cl-containing akaganéite $(\beta-\mathrm{FeOOH})$ : The Antarctic meteorite case. Am. Mineral. 74, 656-667 (1989)

P.R. Buseck, E.F. Holdsworth, Mineralogy and petrology of the Yilmia enstatite chondrite. Meteoritics 7, 429-447 (1972)

R.N. Clayton, Oxygen isotopes in meteorites. Annu. Rev. Earth Planet. Sci. 21, 115-149 (1993). doi: 10.1146/annurev.ea.21.050193.000555

J. Crabb, E. Anders, Noble gases in E-chondrites. Geochim. Cosmochim. Acta 45, 2443-2464 (1981). doi: 10.1016/0016-7037(81)90097-1

J.R. Cronin, S. Pizzarello, D.P. Cruikshank, Organic matter in carbonaceous chondrites, planetary satellites, asteroids and comets, in Meteorites and the Early Solar System, ed. by J.F. Kerridge, M.S. Matthews (University of Arizona Press, Tucson, 1988), pp. 819-857

A.M. Davis, Volatile evolution and loss, in Meteorites and the Early Solar System II, ed. by D.S. Lauretta, H.Y. McSween (University of Arizona Press, Tucson, 2006), pp. 295-307

C.J. Derham, J.E. Geake, G. Walker, Luminescence of enstatite achondrite meteorites. Nature 203, 134-136 (1964). doi:10.1038/203134b0

T.M. Donahue, J.B. Pollack, Origin and evolution of the atmosphere of Venus, in Venus, ed. by D.M. Hunten, L. Colin, T.M. Donahue, V.I. Moroz (University of Arizona Press, Tucson, 1983), pp. 1003-1036

J.A.V. Douglas, A.G. Plant, Amphibole: First occurrence in an enstatite chondrite. Meteoritics 4, 166 (1969). Abstract

A. El Goresy, H. Yabuki, K. Ehlers, D. Woolum, E. Pernicka, Qingzhen and Yamato-691: A tentative alphabet for the EH chondrites. Proc. NIPR Symp. Antarct. Met. 1, 65-101 (1988)

B. Fegley, Primordial retention of nitrogen by terrestrial planets and meteorites. Proc. Lunar Planet. Sci. Conf. 13, A853-A868 (1983)

T. Fouchet, E. Lellouch, B. Bézard, T. Encrenaz, P. Drossart, H. Feuchtgruber, T. de Graauw, ISO-SWS observations of Jupiter: Measurement of the ammonia tropospheric profile and of the ${ }^{15} \mathrm{~N} /{ }^{14} \mathrm{~N}$ isotopic ratio. Icarus 143, 223-243 (2000). doi:10.1006/icar.1999.6255

G.G. Goles, E. Anders, Abundances of iodine, tellurium and uranium in meteorites. Geochim. Cosmochim. Acta 26, $723-737$ (1962). doi:10.1016/0016-7037(62)90035-2

G.G. Goles, L.P. Greenland, D.Y. Jérome, Abundances of chlorine, bromine and iodine in meteorites. Geochim. Cosmochim. Acta 31, 1771-1787 (1967). doi:10.1016/0016-7037(67)90121-4

M.M. Grady, I.P. Wright, L.P. Carr, C.T. Pillinger, Compositional differences in enstatite chondrites based on carbon and nitrogen stable isotope measurements. Geochim. Cosmochim. Acta 50, 2799-2813 (1986). doi:10.1016/0016-7037(86)90228-0 
L. Greenland, J.F. Lovering, Minor and trace element abundances in chondritic meteorites. Geochim. Cosmochim. Acta 29, 821-858 (1965). doi:10.1016/0016-7037(65)90082-7

J.N. Grossman, A.E. Rubin, E.R. Rambaldi, R.S. Rajan, J.T. Wasson, Chondrules in the Qingzhen type-3 enstatite chondrite: Possible precursor components and comparison to ordinary chondrite chondrites. Geochim. Cosmochim. Acta 49, 1781-1795 (1985). doi:10.1016/0016-7037(85)90149-8

K. Hashizume, M. Chaussidon, B. Marty, F. Robert, Solar wind record on the Moon: Deciphering presolar from planetary nitrogen. Science 290, 1142-1145 (2000). doi:10.1126/science.290.5494.1142

E. Jagoutz, H. Palme, H. Baddenhausen, K. Blum, M. Cendales, G. Dreibus, B. Spettel, V. Lorenz, H. Wänke, The abundances of major, minor, and trace elements in the earth's mantle as derived from primitive ultramafic nodules. Proceedings of the 10th Lunar and Planetary Science Conference, 20312050 (1979)

M. Javoy, The integral enstatite chondrite model of the Earth. Geophys. Res. Lett. 22, 2219-2222 (1995). doi:10.1029/95GL02015

G.W. Kallemeyn, J.T. Wasson, Compositions of enstatite (EH3, EH4, 5 and EL6) chondrites: Implications regarding their formation. Geochim. Cosmochim. Acta 50, 2153-2164 (1986). doi:10.1016/00167037(86)90070-0

K. Keil, Quantitativ-erzmikroskopische Integrationsanalyse der Chondrite. Chem. Erde. 22, 281-348 (1962)

K. Keil, Mineralogical and chemical relationships among enstatite chondrites. J. Geophys. Res. 73, 69456976 (1968). doi:10.1029/JB073i022p06945

$\mathrm{K}$. Keil, Occurrence and origin of keilite, $\left(\mathrm{Fe}_{>0.5}, \mathrm{Mg}_{<0.5}\right) \mathrm{S}$, in enstatite chondrite impact-melt rocks and impact-melt breccias. Chem. Erde. 67, 37-54 (2007). doi:10.1016/j.chemer.2006.05.002

J.F. Kerridge, Secular variations in composition of the solar wind: Evidence and causes, in The Ancient Sun, ed. by R.O. Pepin, J.A. Eddy, R.B. Merrill (Pergamon Press, New York, 1980), pp. 475-489

L.K. Kinsey, T.J. McCoy, K. Keil, D.D. Bogard, D.H. Garrison, K. Kehm, R.H. Brazzle, C.M. Hohenberg, D.W. Mittlefehldt, I. Casanova, Petrology, chemistry and chronology of an impact-melt clast in the Hvittis EL6 chondrite. Lunar Planet. Sci. 26, 753-754 (1995). Abstract

C.C. Kung, R.N. Clayton, Nitrogen abundances and isotopic compositions in stony meteorites. Earth Planet. Sci. Lett. 38, 421-435 (1978). doi:10.1016/0012-821X(78)90117-6

J.W. Larimer, M. Bartholomay, The role of carbon and oxygen in cosmic gases: Some applications to the chemistry and mineralogy of enstatite chondrites. Geochim. Cosmochim. Acta 43, 1455-1466 (1979). doi:10.1016/0016-7037(79)90140-6

J.M. Lattimer, D.N. Schramm, L. Grossman, Condensation in supernova ejecta and isotopic anomalies in meteorites. Astrophys. J. 219, 230-249 (1978). doi:10.1086/155771

D.S. Lauretta, K. Lodders, B. Fegley, Experimental simulations of sulfide formation in the solar nebula. Science 277, 358-360 (1997). doi:10.1126/science.277.5324.358

M.R. Lee, S.S. Russell, J.W. Arden, C.T. Pillinger, Nierite $\left(\mathrm{Si}_{3} \mathrm{~N}_{4}\right)$, a new mineral from ordinary and enstatite chondrites. Meteoritics 30, 387-398 (1995)

Y. Lin, A. El Goresy, A comparative study of opaque phases in Qingzhen (EH3) and MacAlpine Hills 88136 (EL3): Representatives of EH and EL parent bodies. Meteorit. Planet. Sci. 37, 577-599 (2002). doi: 10.1016/S0032-0633(02)00037-5

Y. Lin, M. Kimura, Petrographic and mineralogical study of new EH melt rocks and a new enstatite chondrite grouplet. Meteorit. Planet. Sci 33, 501-511 (1998)

Y.T. Lin, H.-J. Nagel, L.L. Lundberg, A. El Goresy, MAC88136-The first EL3 chondrite. Lunar Planet. Sci. 22, 811-812 (1991). Abstract

K. Lodders, Solar system abundances and condensation temperatures of the elements. Astrophys. J. 591, 1220-1247 (2003). doi:10.1086/375492

K. Lodders, S. Amari, Presolar grains from meteorites: Remnants from the early times of the solar system. Chem. Erde. 65, 93-166 (2005). doi:10.1016/j.chemer.2005.01.001

T.J. McCoy, K. Keil, D.D. Bogard, D.H. Garrison, I. Casanova, M.M. Lindstrom, A.J. Brearley, K. Kehm, R.H. Nichols, C.M. Hohenberg, Origin and history of impact-melt rocks of enstatite chondrite parentage. Geochim. Cosmochim. Acta 59, 161-175 (1995). doi:10.1016/0016-7037(94)00231-A

A. Meibom, A.N. Krot, F. Robert, S. Mostefaoui, S.S. Russell, M.I. Petaev, M. Gounelle, Nitrogen and carbon isotopic composition of the Sun inferred from a high-temperature solar nebular condensate. Astrophys. J. 656, L33-L36 (2007). doi:10.1086/512052

R.K. Mohapatra, S.V.S. Murty, Precursors of Mars: Constraints from nitrogen and oxygen isotopic compositions of Martian meteorites. Meteorit. Planet. Sci. 38, 225-241 (2003)

R.K. Mohapatra, S.V.S. Murty, Nitrogen isotopic composition of the MORB mantle: A reevaluation. Geochem. Geophys. Geosyst. 5, Q01001 (2004). doi:10.1029/2003GC000612

R.K. Mohapatra, S. Hermann, U. Ott, Nitrogen, argon and xenon in Happy Canyon E chondrite. Lunar Planet. Sci. 34, abstract\# 1554, Lunar and Planetary Institute, Houston (2003) 
S. Mostefaoui, E. Zinner, P. Hoppe, F.J. Stadermann, A. El Goresy, In situ survey of graphite in unequilibrated chondrites: Morphologies, C, N, O, and H isotopic ratios. Meteorit. Planet. Sci. 40, 721-743 (2005)

D.W. Muenow, K. Keil, L. Wilson, High-temperature mass spectrometric degassing of enstatite chondrites: Implications for pyroclastic volcanism on the aubrite parent body. Geochim. Cosmochim. Acta 56, 4267-4280 (1992). doi:10.1016/0016-7037(92)90267-M

E. Olsen, J.S. Huebner, J.A.V. Douglas, A.G. Plant, Meteoritic amphiboles. Am. Mineral. 58, 869-872 (1973)

T. Owen, P.R. Mahaffy, H.B. Niemann, S. Atreya, M. Wong, Protosolar nitrogen. Astrophys. J. 553, L77-L79 (2001). doi:10.1086/320501

H. Palme, J.W. Larimer, M.E. Lipschutz, Moderately volatile elements, in Meteorites and the Early Solar System, ed. by J.F. Kerridge, M.S. Matthews (University of Arizona Press, Tucson, 1988), pp. 436-460

A. Patzer, J. Schlüter, L. Schultz, M. Tarkian, D.H. Hill, W.V. Boynton, New findings for the unequilibrated enstatite chondrite Grein 002. Meteorit. Planet. Sci. 39, 1555-1575 (2004)

V.K. Pearson, M.A. Sephton, I.A. Franchi, J.M. Gibson, I. Gilmour, Carbon and nitrogen in carbonaceous chondrites: Elemental abundances and stable isotopic compositions. Meteorit. Planet. Sci. 41, 18991918 (2006)

M.I. Petaev, A.K. Lavrukhina, I.L. Khodakovskiy, The origins of minerals in enstatite meteorites. Geochem. Int. 24, 1-12 (1987)

S. Pizzarello, G.W. Cooper, G.J. Flynn, The nature and distribution of the organic material in carbonaceous chondrites and interplanetary dust particles, in Meteorites and the Early Solar System II, ed. by D.S. Lauretta, H.Y. McSween (University of Arizona Press, Tucson, 2006), pp. 625-651

M. Quijano-Rico, H. Wänke, Determination of boron, lithium and chlorine in meteorites, in Meteorite Research, ed. by P.M. Millman (Reidel, Dordrecht, Holland, 1969), pp. 132-145

P. Ramdohr, The Opaque Minerals in Stony Meteorites (Elsevier, Amsterdam, 1973), p. 245

G.W. Reed, Fluorine in stone meteorites. Geochim. Cosmochim. Acta 28, 1729-1743 (1964). doi: 10.1016/0016-7037(64)90019-5

G.W. Reed, R.O. Allen, Halogens in chondrites. Geochim. Cosmochim. Acta 30, 779-800 (1966). doi: 10.1016/0016-7037(66)90132-3

S.J.B. Reed, Perryite in the Kota-Kota and South Oman enstatite chondrites. Mineral. Mag. 36, 850-854 (1968). doi:10.1180/minmag.1968.036.282.13

F. Robert, S. Epstein, Carbon, hydrogen, and nitrogen isotopic compositions of the Renazzo and Orgueil organic components. Meteoritics 15, 355-356 (1980)

F. Robert, R.H. Becker, S. Epstein, Hydrogen, carbon and nitrogen isotopes in organic extracts and HFtreated residues of the Murchison and Murray meteorites. Lunar Planet. Sci. 11, 935-937 (1980). Abstract

A.E. Rubin, Impact melt-rock clasts in the Hvittis enstatite chondrite breccia: Implications for a genetic relationship between EL chondrites and aubrites. Proceedings of the Lunar Planetary Science Conference 14th, B293-B300 (1983a)

A.E. Rubin, The Atlanta enstatite chondrite breccia. Meteoritics 18, 113-121 (1983a)

A.E. Rubin, The Adhi Kot breccia and implications for the origin of chondrules and silica-rich clasts in enstatite chondrites. Earth Planet. Sci. Lett. 64, 201-212 (1983b). doi:10.1016/0012-821X(83)90204-2

A.E. Rubin, The Blithfield meteorite and the origin of sulfide-rich, metal-poor clasts and inclusions in brecciated enstatite chondrites. Earth Planet. Sci. Lett. 67, 273-283 (1984). doi:10.1016/0012-821X (84) $90167-5$

A.E. Rubin, Sinoite $\left(\mathrm{Si}_{2} \mathrm{~N}_{2} \mathrm{O}\right)$ : Crystallization from EL chondrite impact melts. Am. Mineral. 82, 1001-1006 (1997a)

A.E. Rubin, Igneous graphite in enstatite chondrites. Mineral. Mag. 61, 699-703 (1997b). doi:10.1180/ minmag.1997.061.408.09

A.E. Rubin, Mineralogy of meteorite groups. Meteorit. Planet. Sci. 32, 231-247 (1997c)

A.E. Rubin, Shock and annealing in EL chondrites. Meteorit. Planet. Sci. 41, A154 (2006). doi:Abstract

A.E. Rubin, Shock, brecciation, impact-melting and post-shock annealing in aubrites. Meteorit. Planet. Sci. (submitted) (2009)

A.E. Rubin, E.R.D. Scott, Abee and related EH chondrite impact-melt breccias. Geochim. Cosmochim. Acta 61, 425-435 (1997). doi:10.1016/S0016-7037(96)00335-3

A.E. Rubin, E.R.D. Scott, K. Keil, Shock metamorphism of enstatite chondrites. Geochim. Cosmochim. Acta 61, 847-858 (1997). doi:10.1016/S0016-7037(96)00364-X

A.E. Rubin, H. Huber, J.T. Wasson, Possible impact-induced refractory-lithophile fractionations in EL chondrites. Geochim. Cosmochim. Acta 73, 1523-1537 (2009). doi:10.1016/j.gca.2008.12.002

S.S. Russell, M.R. Lee, J.W. Arden, C.T. Pillinger, The isotopic compositions and origins of silicon nitride from ordinary and enstatite chondrites. Meteoritics 30, 399-404 (1995) 
M.A. Sephton, A.B. Verchovsky, P.A. Bland, I. Gilmour, M.M. Grady, I.P. Wright, Investigating the variations in carbon and nitrogen isotopes in carbonaceous chondrites. Geochim. Cosmochim. Acta 67, 2093-2108 (2003). doi:10.1016/S0016-7037(02)01320-0

F. Vilas, Mercury: Absence of crystalline $\mathrm{Fe}^{2+}$ in the regolith. Icarus 64, 133-138 (1985). doi:10.1016/ 0019-1035(85)90044-2

H.R. von Gunten, A. Wyttenbach, W. Scherle, Determination of chlorine in stony meteorites by neutron activation analysis. Geochim. Cosmochim. Acta 29, 475-480 (1965). doi:10.1016/0016-7037(65) 90041-4

J.T. Wasson, The building stones of the planets, in Mercury, ed. by F. Vilas, C.R. Chapman, M.S. Matthews (University of Arizona Press, Tucson, 1988), pp. 622-650

J.T. Wasson, G.W. Kallemeyn, Compositions of chondrites. Philos. Trans. R. Soc. Lond. A325, 535-544 (1988)

J.T. Wasson, G.W. Kallemeyn, A.E. Rubin, Equilibration temperatures of EL chondrules: A major downward revision in the ferrosilite contents of enstatite. Meteoritics 29, 658-662 (1994)

M. Womack, S. Wyckoff, L.M. Ziurys, Observational constraints on solar nebula nitrogen chemistry: N2/NH3. Astrophys. J. 401, 728-735 (1992). doi:10.1086/172100 